\title{
PENGARUH KOMPENSASI, INSENTIF, DAN GAYA KEPEMIMPINAN TERHADAP KINERJA KARYAWAN PT. CIPTA AGRO SEJATI, ROKAN HILIR, RIAU
}

\author{
Erick Jessino $^{1)}$, Demak Claudia Yosephine Simanjuntak ${ }^{2)}$ \\ Fakultas Ekonomi, Universitas Prima Indonesia \\ claudiayoseph8@gmail.com
}

\begin{abstract}
Conducting tests by analyzing the influence of compensation, incentives and leadership styles on employee performance at PT. Cipta Agro Sejati, Rokan Hilir, Riau is the objective of this research. The decline that occurs in employee performance can be assessed from the achievement of company targets, which is caused by unsatisfactory compensation and incentives and ineffective leadership. The research method uses quantitative. The population taken by the researcher is 196 employee subjects and the sample used is 132 employees. Sampling random sampling is the sampling technique used. In calculating the hypothesis test obtained individually, the value of tcount $>$ ttable or $3.887>1.979$ is obtained from the significance that is obtained $0.0 \neg 00<0.05$, meaning that Ha accepted while Ho was rejected, namely by individual Compensation had a significant positive effect on the Employee Performance of PT. Cipta Agro Sejati, Rokan Hilir, Riau. The results in calculating the hypothesis test with individuals and simultaneously Compensation, Incentives, and Leadership Style have a significant positive effect on the Employee Performance of PT. Cipta Agro Sejati, Rokan Hilir, Riau.
\end{abstract}

Keywords: Compensation, Incentives, Leadership Style, Employee Performance

\section{PENDAhuluaN}

Dewasa ini ketika menghadapi persaingan yang semakin besar banyak perusahaan di haruskan untuk dapat mengefektif dan mengefisienkan sumber daya yang terdapat didalam sebuah perusahaan. Daya saing di bidang kelapa sawit yang cukup ketat dan tinggi perlu didukungnya kinerja yang optimal dari para karyawan pada suatu perusahaan. Kinerja Karyawan mengalami penurunan nampak dari penurunan kualitas kerja karyawan yang tercermin dari peningkatan kesalahan kerja karyawan dalam melaksanakan tugasnya. Hal ini memicu belum tercapainya target perusahaan.

Kompensasi yang diterima karyawan didalam perusahaan. Permasalahan karyawan memperoleh kompensasi yang tak diharapkan melalui apa yang telah dipertaruhkan pada pihak perusahaan. Dimana kenaikan gaji yang kecil, insentif yang diberikan kepada karyawan marketing yang rendah yang tidak sebanding dengan target penjualan yang tinggi, bonus yang diberikan tidak merata, dan uang kerajinan yang diberikan tidak untuk semua bagian hanya di beberapa bagian seperti bagian gudang dan pengiriman. 
Tabel 1.

Data Kompensasi Tahun 2020

\begin{tabular}{|c|c|c|c|r|}
\hline Divisi & Jabatan & Masa Kerja & Gaji/ bulan & Uang Makan / Hari \\
\hline \multirow{4}{*}{ Gudang } & Kepala Gudang & 5 Tahun & Rp. 2.150.000,- & Rp 10.000 \\
\cline { 2 - 5 } & Staf Gudang & 4 Tahun & Rp. 1.800.000,- & Rp 10.000 \\
\cline { 2 - 5 } & Staf Gudang & 3 Tahun & Rp. 1.800.000,- & Rp 10.000 \\
\cline { 2 - 5 } & Staf Gudang & 3 Tahun & Rp. 1.600.000,- & Rp 10.000 \\
\hline \multirow{4}{*}{ Supir } & Supir & 2 Tahun & Rp. 1.100.000,- & Rp 10.000 \\
\cline { 2 - 5 } & Supir & 1 Tahun & Rp. 1.000.000,- & Rp 10.000 \\
\cline { 2 - 5 } & Supir & 1 Tahun & Rp. 920.000,- & Rp 10.000 \\
\cline { 2 - 5 } & Supir & 1 Tahun & Rp. 900.000,- & Rp 10.000 \\
\hline \multirow{2}{*}{ Keuangan } & Staf Pajak & 2 Tahun & Rp. 1.900.000,- & Rp 10.000 \\
\hline \multirow{2}{*}{ Marketing } & Staf Adminitrasi & 1 Tahun & Rp. 1.700.000,- & Rp 10.000 \\
\cline { 2 - 5 } & Staf Sales & 2 Tahun & Rp. 1.850.000,- & Rp 10.000 \\
\cline { 2 - 5 } & Staf Sales & 1 Tahun & Rp. 1.600.000,- & \\
\hline
\end{tabular}

Sumber: PT. Cipta Agro Sejati, 2020

Permasalahan insentif dalam perusahaan PT. Cipta Agro Sejati, Rokan Hilir, Riau adalah besarnya insentif ternyata juga sebagai faktor yang salah satunya dapat mempengaruhi terjadinya penurunan Kinerja Karyawan pada perusahaan ini. Permasalahan insentif PT. Cipta Agro Sejati, Rokan Hilir, Riau adalah sedikitnya pemberian insentif. Besarnya insentif yang diberikan setiap karyawan berbeda sehingga banyak karyawan yang tidak memahami perhitungan insentif dan cara pengukuran yang diterima kecuali untuk insentif bagian pemasaran atau marketing, banyak karyawan yang sulit untuk mencapai target kerja terlihat dari banyak karyawan yang tidak menerima insentif setiap bulannya, Insentif untuk bagian back office perhitungan nya rumit dan tidak diberitahukan cara menghitungnya, sehingga karyawan banyak yang tidak tahu bagaimana cara mendapatkannya.Berikut data grafik pemberian insentif/upah lembur PT. Cipta Agro Sejati, Riau bulan Januari sampai dengan Desember 2020, data grafik dibawah ini.

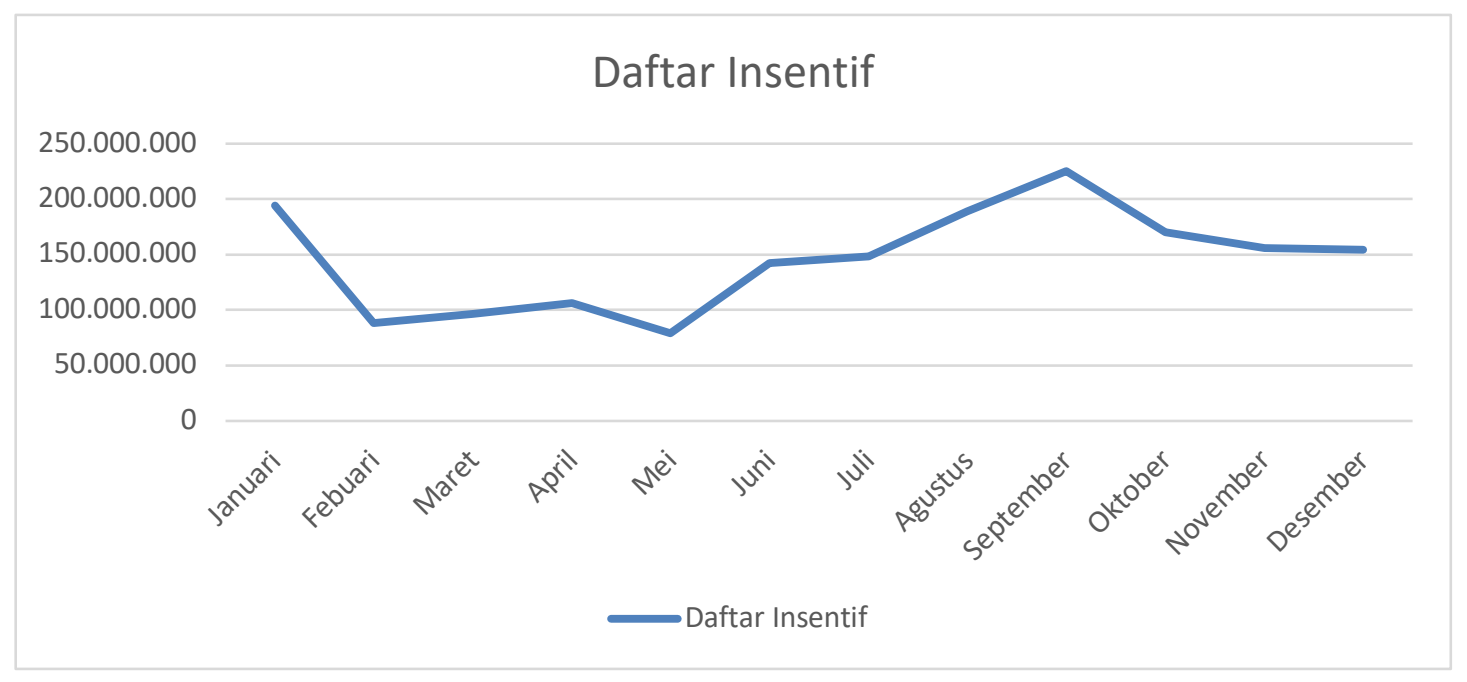

Sumber: PT. Cipta Agro Sejati, 2020

Gambar 1. Insentif Karyawan 
Permasalahan kepemimpinan di dalam PT. Cipta Agro Sejati, Rokan Hilir, Riauadalah pemimpinnya belum mampu mememberiksn motivasi bagi pekerjanya dimana menyebabkan ketidakmampuan guna mencapai target yang diinginkan, berkurangnya komunikasi yang dilakukan Atasan kepada karyawan, pemimpin yang hanya mementingkan profit perusahan dan tidak ingin mengetahui bermacam kendala yang akan dihadapi karyawan dalam pekerjaan mereka serta pemimpin yang kurang dapat mengontrol emosi.

Dari permasalahan diatas peneliti merasa perlu melakukan dengan judul: "Pengaruh Kompensasi, Insentif, dan Gaya Kepemimpinan terhadap Kinerja Karyawan PT. Cipta Agro Sejati, Rokan Hilir, Riau."

Adapun perumusan masalahnya yaitu:

1. Bagaimana pengaruh Kompensasi pada Kinerja Karyawan PT. Cipta Agro Sejati, Rokan Hilir, Riau?

2. Bagaimana pengaruh Insentif pada Kinerja Karyawan PT. Cipta Agro Sejati, Rokan Hilir, Riau?

3. Bagaimana pengaruh Gaya Kepemimpinan pada Kinerja Karyawan PT. Cipta Agro Sejati, Rokan Hilir, Riau?

4. Bagaimana pengaruh Kompensasi, Insentif, dan Gaya Kepemimpinan pada Kinerja Karyawan PT. Cipta Agro Sejati, Rokan Hilir, Riau?

Adapun tujuan penelitian dilaksanakan guna:

1. Menguji serta menganalisis pengaruh Gaya Kepemimpinan pada Kinerja Karyawan PT. Cipta Agro Sejati, Rokan Hilir, Riau.

2. Menguji serta menganalisis pengaruh Insentif pada Kinerja Karyawan PT. Cipta Agro Sejati, Rokan Hilir, Riau.

3. Menguji serta menganalisis pengaruh Gaya Kepemimpinan pada Kinerja Karyawan PT. Cipta Agro Sejati, Rokan Hilir, Riau.

4. Menguji serta menganalisis pengaruh Kompensasi, Insentif dengan Gaya Kepemimpinan pada Kinerja Karyawan PT. Cipta Agro Sejati, Rokan Hilir, Riau.

\section{KAJIAN LITERATUR}

Mengacu (Edison et al., 2016:164), kelayakan kompensasi menyebabkan individu lebih bersemangat guna peningkatan keahlian yang dimiliki, bahkan membuat komitmen terhadap organisasi atau perusahaan semakin kuat, oleh karenanya berakhir dengan peningkatan kinerja organisasi atau perusahaan termasuk individunya. Mengacu (Wibowo, 2014:289), kenyataan di kapangan, masing-masing perusahaan melakukan penerapan sistem kompensasi dengan bebas dan fleksibel menyesuaikan kondisinya. Dimana diambil sistem yang dianggap paling sesuai guna pemberian kompensasi bagi karyawan agar kinerja bisa meningkat dan karyawan juga puas.

Mengacu (Priansa, 2016:336), insentif material dari perusahaan harus berdasarkan pertimbangan kinerja. Wujudnya berupa pembayaran mengacu kinerja yang dilakukan ketika di perusahaan. Mengacu (Yani, 2012:176), sistem insentif merujuk hubungan paling jelas prestasi dan kompensasi kerja istilah sistem insentif secara umum dimanfaatkan guna penggambaran seluruh rencana upah yang dibayarkan berkaitan langsung ataupun tidak langsung melalui macam-macam standart produktivitas karyawan.

Menurut (Bangun, 2018:339-340), Manajer mengerjakan tugas kepemimpinan supaya anggota organisasi bisa menjalankan tugas menyesuaikan fungsi yang diberikan. Segala metode bisa dilaksanakan guna mempengaruhi orang lain agar menciptakan rasa 
tanggung jawab bagi para anggotanya atas pekerjaanya. Keberhasilan manajer menjalankan tugas kepemimpinan mampu membuat semangat kerja para anggotanya tumbuh yang akhirnya membuat kinerja mengalami peningkatan. Kepemimpinan menjadi sebuah faktor penting guna penentuan perilaku kelompok beserta individu dalam organisasi. Dampak kesalahan ketika menentukan gaya kepemimpinan yakni kinerja yang menurun, tingkat absensi yang tinggi dan perputaran. Mengacu (Robbins \& Coulter, 2013:157), kepemimpinan memberikan dukungan agar kinerja yang dihasilkan karyawan tinggi begitupun tingkat kepuasannya terhadap pekerjaan. Hal ini terjadi bilamana pekerjaan yang dilaksanakan karyawan memiliki struktur yang baik.

\section{Kerangka Konsepsual}

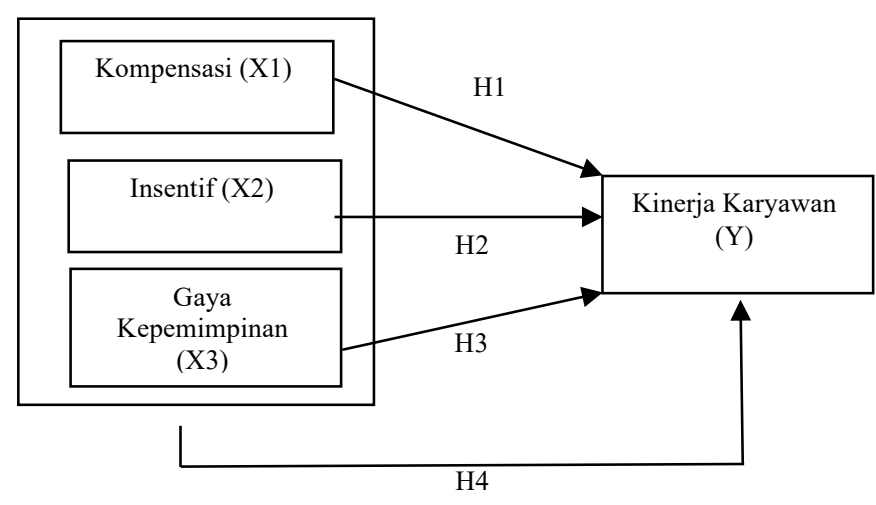

Gambar 2. Kerangka Konseptual

Dengan kerangka konsepsual yang telah disajikan sehingga hipotesis yang dilakukan pengajuan peneliti yakni:

H1: Secara parsial Kompensasi berpengaruh terhadap Kinerja Karyawan PT. Cipta Agro Sejati, Rokan Hilir, Riau.

H2: Secara parsial Insentif berpengaruh terhadap Kinerja Karyawan PT. Cipta Agro Sejati, Rokan Hilir, Riau.

H3: Secara parsial Gaya Kepemimpinan berpengaruh terhadap Kinerja Karyawan PT. Cipta Agro Sejati, Rokan Hilir, Riau.

H4: Secara simultan Kompensasi, Insentif dan Gaya Kepemimpinan berpengaruh terhadap Kinerja Karyawan PT. Cipta Agro Sejati, Rokan Hilir, Riau.

\section{METODE}

Pada penelitian yang dilaksanakan, penulis memanfaatkan metode penelitian deskriptif kuantitatif. Mengacu (Arikunto, 2016:3) penelitian deskriptif ialah kajian yang memanfaatkan penelitian korelasi dimana tujuannya yakni guna pencarian pengaruh antara variabel yang satu sama lain. Pendekatan penelitian ini berdasarkan pendekatan kuantitatif. Mengacu (Sangagji, 2016:288) menjelaskan bahwa penelitian kuantitatif diartikan berpedoman data yang dalam penafsirannya bisa dilakukan melalui perhitungan. Sifat penelitian yang dimanfaatkan yakni deskriptif explanatory dimana tujuannya memberi gambaran kedudukandan hubungan keseluruhan variabel penelitian. 


\section{Populasi}

Mengacu (Arikunto, 2016:173), Populasi ialah seluruh subjek penelitian. Pada penelitian ini jumlah populasinya yakni 196 karyawan PT. Cipta Agro Sejati.

\section{Sampel}

Mengacu (Sunyoto, 2012:48), "Sampel ialah bagian populasi dengan karakteristik yang sudah ditetapkan peneliti, dan dinilai mampu terwakili keseluruhan populasi." Teknik dalam mengambil sampel yang dimanfaatkan ialah sampling random sampling, guna menetapkan jumlah sampel memanfaatkan formula Slovin yakni:

Dimana:

$\mathrm{n} \quad=$ Ukuran Sampel

$\mathrm{N} \quad=$ Populasi

$\mathrm{e} \quad=$ Prosentasi kelonggaran tidak keterikatan sebab kekeliruan dalam mengambil sampel yang dikehendaki.

Mengacu yang sudah dihitung sebelumnya didapatkan sampel dengan jumlahnya yakni 132 karyawan PT. Cipta Agro Sejati, dan guna uji reliabilitas dan validitas sebanyak 30 pelanggan diluar dari sampel penelitian.

\section{Teknik Pengumpulan Data}

Pada penelitian yang dilaksanakan, memanfaatkan 3 teknik guna mengumpulkan datanya meliputi:

1. Kuesioner, dibagikan kepada karyawan penelitian.

2. Wawancara, dilakukan kepada beberapa karyawan.

3. Studi dokumentasi yang digunakan.

\section{Jenis dan Sumber Data}

Sumber data dalam penelitian ini adalah:

1. Data Primer diperoleh dengan wawancara dan kuesioner penelitian yang dibagikan kepada karyawan

2. Data Sekunder contohnya buku-buku dan jurnal yang berkaitan dengan penelitian ini. 
Tabel 2.

Definisi Operasional dan Pengukuran Variabel

\begin{tabular}{|c|c|c|c|}
\hline Variabel & Definisi & Indikator & $\begin{array}{c}\text { Skala } \\
\text { Pengukuran }\end{array}$ \\
\hline $\begin{array}{c}\text { Kompensasil } \\
\left(\mathrm{X}_{1}\right)\end{array}$ & $\begin{array}{lr}\text { Bentuk } & \text { apresiasi } \\
\text { perusahaan } & \text { kepada } \\
\text { tenaga kerja } & \text { yang telah } \\
\text { memberikan } & \text { segenap } \\
\text { tenaga dan } & \text { pemikiran } \\
\text { mereka } & \text { demi } \\
\text { perusahaan. } & \\
\text { Sumber: (Esti et al., } \\
\text { 2019) }\end{array}$ & $\begin{array}{l}\text { 1. Gaji } \\
\text { 2. Insentif } \\
\text { 3. Bonus } \\
\text { 4. Upah } \\
\text { 5. Premi } \\
\text { 6. Pengobatan/Asuransi } \\
\text { Sumber: (Sudarmin Manik, 2016) }\end{array}$ & Skala Likert \\
\hline $\begin{array}{c}\text { Insenitf } \\
\left(X_{2}\right)\end{array}$ & \begin{tabular}{lr}
\multicolumn{3}{l}{ Bentuk penghargaan atas } \\
prestasi kinerjanya. satu \\
penghargaan yang \\
dikaitkan & dengan \\
prestasi kerja. & Prestasi \\
kerja yang semakin \\
bagus akan membuat \\
isnentif yang diberikan \\
pun semakin tinggi. \\
\\
Sumber: \\
$2012: 145$ )
\end{tabular} & $\begin{array}{l}\text { 1. Berdasarkan kinerja pegawai } \\
\text { 2. Lama kerja } \\
\text { 3. Senioritas } \\
\text { 4. Kebutuhan } \\
\text { 5. Keadilan dan kelayakan } \\
\text { 6. Evaluasi jabatan } \\
\text { Sumber: (Rahayu \& Ruhamak, 2017) }\end{array}$ & $\begin{array}{l}\text { Skala } \\
\text { Likert }\end{array}$ \\
\hline $\begin{array}{c}\text { Gaya } \\
\text { Kepemimpinan } \\
\left(\mathrm{X}_{3}\right)\end{array}$ & $\begin{array}{lr}\text { Bagaimana } & \text { seorang } \\
\text { pemimpin perusahaan } \\
\text { melakukan tugasnya } \\
\text { dalam memimpin dan } \\
\text { bagaimana mereka } \\
\text { dipandang r oleh } \\
\text { karyawan yang sedang di } \\
\text { pimpin atau kepada } \\
\text { mereka yang sedang } \\
\text { memantau dari luar. } \\
\\
\text { Sumber: (Sunarsi, 2018) }\end{array}$ & $\begin{array}{l}\text { 1. Menyusun rencana kerja } \\
\text { 2. Memberi petunjuk atau pengarahan } \\
\text { kepada pegawai } \\
\text { 3. Melakukan pengawasan terhadap } \\
\text { pelaksanaan tugas pegawai } \\
\text { 4. Memberikan motivasi kepada } \\
\text { bawahan } \\
\text { 5. Melibatkan bawahan dalam } \\
\text { pengambilan keputusan } \\
\text { 6. Mengembangkan hubungan yang } \\
\text { bersahabat } \\
\text { Sumber: (Yancomala, 2014) }\end{array}$ & $\begin{array}{l}\text { Skala } \\
\text { Likert }\end{array}$ \\
\hline $\begin{array}{l}\text { Kinerja } \\
\text { Karyawan } \\
\text { (Y) }\end{array}$ & $\begin{array}{lr}\text { Pencapaian } & \text { berupa } \\
\text { prestasi kerja } & \text { bagi } \\
\text { karyawan yang } & \text { telah } \\
\text { mengerjakan } & \text { tugas } \\
\text { berdasarkan tanggung } \\
\text { jawab yang telah } \\
\text { diberikan. } \\
\\
\text { Sumber: (Husain, 2020) }\end{array}$ & $\begin{array}{l}\text { 1. Jumlah pekerjaan } \\
\text { 2. Kualitas pekerjaan } \\
\text { 3. Ketepatan waktu } \\
\text { 4. Kehadiran } \\
\text { 5. Kemampuan dan kerjasama } \\
\text { Sumber: (Wijaya et al., 2012) }\end{array}$ & $\begin{array}{l}\text { Skala } \\
\text { Likert }\end{array}$ \\
\hline
\end{tabular}




\section{Uji Validitas}

Menurut (Priyanto, 2018:20), uji validtas item dimanfaatkan guna melihat tingkat kecermatan pengukuran pada keseluruhan item. Kemudian uji signifikan yang dilaksanakan melalui $r_{\text {tabel }}$ dengan tingkatan signifikansinya 0,05 memanfaatkan pengujian 2 sisi.

1. Jika nilai positif $r_{\text {hitung }}>r_{\text {tabel }}$ item diartikan valid.

2. Jika nilai $\mathrm{r}_{\text {hitung }}<\mathrm{r}_{\text {tabel }}$ item diartikan tak valid.

\section{Uji Reliabilitas}

Mengacu (Priyanto, 2018:25), uji reliabilitas dimanfaatkan guna melihat alat pengukuran apakah konsisten ataukah tidak, dimana umumnya memanfaatkan kuesioner. Metode yang umum diguakan pada penelitian ini guna pengukuran skala rentang (skala likert 1-5) yaitu Cronbach Alpha. Pengujian reliabilitas menjadi pengujian validitas yang berkelanjutan, konstruk yang termasuk pengujian hanyalah konstruk yang valid dan guna penentuan pakai instrument reliabel atau tidak mengunakan batasan 0,6 .

\section{Uji Normalitas}

Sesuai pemaparan dari (Priyanto, 2018:73), uji normalitas data menjadi sesuatu paling penting sebab data yang distribusinya normal dinilai bisa mewakili populasi.

1. Kolmogorov smirnov, bila signifikansi $\leq 0,05$ didapatkan kesimpulan data tidak berdistribusi normal. Serta bila signifikansinya $>0,05$ didapatkan kesimpulan data dinyatakan distribusi normal.

2. Grafik histogram dan normal probability plot, mengacu (Ghozali, 2016:154), bagian cara guna melihat residual yang normalitas ialah melalui grafik histogram yang membuat perbandingan data pengamatan dengan pendistribusian di kisaran distribusi normal. Dimana pada kondisi normal bisa membuat terbentuknya garis lurus diagonal selanjutnya akan dilakukan perbandingan ploting data residualnya. Bilamana distribusi data residual normal, penggambaran garis data sebenarnya menyesuaikan garis diagonal.

\section{Uji Multikolinearitas}

Sesuai pemparan dari (Ghozali, 2016:103), pengujian multikolonieritas memiliki tujuan guna pengujian apakah model regresi berkorelasi pada seluruh variabel bebas. Multikolonieritas timbul bila nilai tolerance $\geq 0,10$ ataupun nilainya VIF $\leq 10$.

\section{Uji Heteroskedastisitas}

Sesuai pandangan dari (Ghozali, 2016:134), pengujian heteroskedastisitas memiliki tujuan guna melihat permodelan regresi terkait variance dari residual sebuah observasi dengan lainnya yang tidak sama. Terdapat sejumlah cara guna melakukan deteksi gejala heteroskedastisitas yang terjadi yakni melalui grafik Scatterplot dan uji Glejser. Pengujian Glejser mempunyai kriterianya yakni: bila sig $>0,05$ dikatakan tak terjadinya gejala heteroskedastisitas dan bila sig $<0,05$ dikatakan bergejala heteroskedastisitas.

\section{Koefisien Determinasi}

Menurut Sujarweni (2015:164) untuk mengetahui persentase perubahan sebuah variabel tidak bebas (Y) yang di sebabkan oleh variabel bebas (X) ialah menggunakan koefisien determinasi $\left(\mathrm{R}^{2}\right)$. Apabila nilai $\mathrm{R}^{2}$ semakin besar, maka persentase perubahan sebuah variabel tidak bebas $(\mathrm{Y})$ disebabkan oleh variabel bebas $(\mathrm{X})$ semakin meninggi. 


\section{Pengujian Hipotesis Secara Simultan (Uji-F)}

Mengacu (Sujarweni, 2015:137), Pengujian F dimanfaatkan guna melihat pengaruh variabel independen terhadap dependennya secara bersamaan.

1. $\mathrm{H}_{0}: \mathrm{b}_{1}, \mathrm{~b}_{2}, \mathrm{~b}_{3}=0$, (Kompensasi, Insentif, dan Gaya Kepemimpinan tidak mempengaruhi Kinerja Karyawan PT. Cipta Agro Sejati, Rokan Hilir, Riau secara signifikan dan positif)

2. $\mathrm{H}_{\mathrm{a}}: \mathrm{b}_{1}, \mathrm{~b}_{2}, \mathrm{~b}_{3} \neq 0$, (Kompensasi, Insentif, dan Gaya Kepemimpinan mempengaruhi Kinerja Karyawan PT. Cipta Agro Sejati, Rokan Hilir, Riau secara signifikan dan positif.)

$\mathrm{H}_{0}$ diterima jika $\mathrm{F}_{\text {hitung }} \leq \mathrm{F}_{\text {tabel }}$ dengan tingkatan signifikansinya $\alpha=5 \%$

$\mathrm{H}_{\mathrm{a}}$ diterima jika $\mathrm{F}_{\text {hitung }}>\mathrm{F}_{\text {tabel }}$ dengan tingkatan signifikansinya $\alpha=5 \%$

\section{Pengujian Hipotesis Secara Parsial (Uji-t)}

Mengacu (Sujarweni, 2015:118), Uji t dimanfaatkan guna melihat pengaruh atau hubungan yang artinya (signifikan) pada variabel independen terhadap dependennya secara individual. Dimana ketentuannya :

1. $\mathrm{H}_{0}: \mathrm{b}_{1}, \mathrm{~b}_{2}, \mathrm{~b}_{3}=0$, (Kompensasi, Insentif, dan Gaya Kepemimpinan tidak mempengaruhi Kinerja Karyawan PT. Cipta Agro Sejati, Rokan Hilir, Riau secara signifikan dan positif)

2. $\mathrm{H}_{\mathrm{a}}: \mathrm{b}_{1}, \mathrm{~b}_{2}, \mathrm{~b}_{3} \neq 0$, (Kompensasi, Insentif, dan Gaya Kepemimpinan mempengaruhi Kinerja Karyawan PT. Cipta Agro Sejati, Rokan Hilir, Riau secara signifikan dan positif)

Berikutnya keputusan diambil mengacu kriterianya yakni:

$\mathrm{H}_{0}$ diterima bila $\mathrm{t}_{\text {tabel }} \leq \mathrm{t}_{\text {hitung }} \leq \mathrm{t}_{\text {tabel }}$ (dari tingkatan signifikansinya $\alpha=5 \%$ )

$\mathrm{H}_{\mathrm{a}}$ diterima apabila $\mathrm{t}_{\text {hitung }}<-\mathrm{t}_{\text {tabel }}$ ataupun $\mathrm{t}_{\text {hitung }}>\mathrm{t}_{\text {tabel }}$ (dari tingkatan signifikansinya $\alpha=$ $5 \%)$

\section{HASIL DAN DISKUSI}

Adapun statistik deskriptif hasil jawaban para responden, yakni :

Tabel 3.

\section{Statistik Deskriptif}

\begin{tabular}{|l|r|r|r|r|r|}
\hline & N & Minimum & \multicolumn{1}{|c|}{ Maximum } & \multicolumn{1}{c|}{ Mean } & Std. Deviation \\
\hline Kompensasi & 132 & 6 & 30 & 16.80 & 7.492 \\
Insentif & 132 & 9 & 40 & 19.44 & 7.693 \\
Gaya kepemimpinna & 132 & 10 & 50 & 35.51 & 13.304 \\
Kinerja & 132 & 10 & 50 & 25.29 & 11.956 \\
Valid N (listwise) & 132 & & & \\
\hline
\end{tabular}

Sumber: Data primer yang diolah, 2020

Tabel 3 merujuk nilai minimum variabel kompensasinya yakni 6 dan maksimumnya 30 , dimana nilai meannya 16,80 dan standar devitionnya 7,492. Pada variabel insentif nilai minimumnya yakni 9 dan maksimumnya 40, dengan nilai meannya 19,44 dan standar devitionnya 7,693. Pada variabel gaya kepemimpinan nilai minimumnya yakni 10 dan maksimumnya 50, dengan nilai meannya 35,51 dan standar devitionnya 13,304. Pada variabel kinerja karyawan nilai minimumnya 10 dan maksimumnya 50, dengan nilai meannya 25,29 dan standar devitionnya 11,956 . 


\section{Hasil Uji validitas dan Reliabilitas Instrumen Variabel}

Pengujian validitas pun bisa dilaksanakan melalui penghitungan korelasi pada skor tiap item pertanyaan serta jumlah keseluruhan skornya.

Tabel 4.

Hasil Uji Validitas Instrumen Variabel

\begin{tabular}{|c|c|c|c|c|c|c|}
\hline No & Variabel & Pertanyaan & $\begin{array}{c}\text { Total } \\
\text { Correlation }\end{array}$ & $\mathbf{r}_{\text {tabel }}$ & Sig. (2-tailed) & Keterangan \\
\hline \multirow[t]{6}{*}{1.} & \multirow[t]{6}{*}{ Kompensasi } & $\mathrm{X}_{1.1}$ & 0,720 & \multirow{36}{*}{ 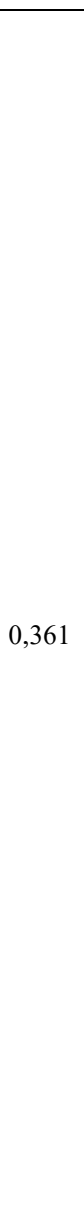 } & \multirow{36}{*}{0,000} & Valid \\
\hline & & $\mathrm{X}_{2.1}$ & 0,751 & & & Valid \\
\hline & & $\mathrm{X}_{3.1}$ & 0,598 & & & Valid \\
\hline & & $\mathrm{X}_{4.1}$ & 0,733 & & & Valid \\
\hline & & $\mathrm{X}_{5.1}$ & 0,725 & & & Valid \\
\hline & & $\mathrm{X}_{6.1}$ & 0,724 & & & Valid \\
\hline \multirow[t]{10}{*}{2.} & \multirow[t]{10}{*}{ Insentif } & $\mathrm{X}_{1.2}$ & 0,770 & & & Valid \\
\hline & & $\mathrm{X}_{2.2}$ & 0,861 & & & Valid \\
\hline & & $\mathrm{X}_{3} .2$ & 0,874 & & & Valid \\
\hline & & $\mathrm{X}_{4.2}$ & 0,854 & & & Valid \\
\hline & & $\mathrm{X}_{5.2}$ & 0,943 & & & Valid \\
\hline & & $\mathrm{X}_{6.2}$ & 0,957 & & & Valid \\
\hline & & $\mathrm{X}_{7.2}$ & 0,933 & & & Valid \\
\hline & & $\mathrm{X}_{8.2}$ & 0,950 & & & Valid \\
\hline & & $\mathrm{X}_{9.2}$ & 0,906 & & & Valid \\
\hline & & $\mathrm{X}_{10.2}$ & 0,960 & & & Valid \\
\hline \multirow[t]{10}{*}{3.} & \multirow[t]{10}{*}{ Gaya Kepemimpinan } & $\mathrm{X}_{1.3}$ & 0,648 & & & Valid \\
\hline & & $\mathrm{X}_{2.3}$ & 0,625 & & & Valid \\
\hline & & $\mathrm{X}_{3.3}$ & 0,771 & & & Valid \\
\hline & & $\mathrm{X}_{4.3}$ & 0,614 & & & Valid \\
\hline & & $\mathrm{X}_{5.3}$ & 0,797 & & & Valid \\
\hline & & $\mathrm{X}_{6.3}$ & 0,618 & & & Valid \\
\hline & & $X_{7.3}$ & 0,694 & & & Valid \\
\hline & & $\mathrm{X}_{8.3}$ & 0,701 & & & Valid \\
\hline & & $\mathrm{X}_{9.3}$ & 0,765 & & & Valid \\
\hline & & $\mathrm{X}_{10.3}$ & 0,766 & & & Valid \\
\hline \multirow[t]{10}{*}{4.} & \multirow[t]{10}{*}{ Kinerja Karyawan } & $\mathrm{Y}_{1}$ & 0,803 & & & Valid \\
\hline & & $\mathrm{Y}_{2}$ & 0,862 & & & Valid \\
\hline & & $\mathrm{Y}_{3}$ & 0,891 & & & Valid \\
\hline & & $\mathrm{Y}_{4}$ & 0,821 & & & Valid \\
\hline & & $\mathrm{Y}_{5}$ & 0,851 & & & Valid \\
\hline & & $\mathrm{Y}_{6}$ & 0,903 & & & Valid \\
\hline & & $Y_{67}$ & 0,844 & & & Valid \\
\hline & & $\mathrm{Y}_{8}$ & 0,724 & & & Valid \\
\hline & & $\mathrm{Y}_{9}$ & 0,846 & & & Valid \\
\hline & & $\mathrm{Y}_{10}$ & 0,843 & & & Valid \\
\hline
\end{tabular}

Sumber: Data primer yang diolah, 2020

Table 4 merujuk pada instrumen yang diuji dari variabel bebas dan terikat menghasilkan adanya nilai $r_{\text {hitung }}$ yang melebihi $r_{\text {tabel }}$ dan nilai sig. dibawah 0,05 . Kesimpulan keseluruhan item kuesioner dinyatakan valid. 
Adapun pengujian reliabilitas yang dihasilkan yakni:

Tabel 5.

Uji Reliabilitas

\begin{tabular}{|l|c|c|c|}
\hline \multicolumn{1}{|c|}{ Variabel } & Cronbach's Alpha & Nof Items & Keterangan \\
\hline Kompensasi & 0,961 & 8 & Handal \\
\hline Insentif & 0,979 & 8 & Handal \\
\hline Gaya Kepemimpinan & 0,843 & 10 & Handal \\
\hline Kinerja Karyawam & 0,953 & 10 & Handal \\
\hline
\end{tabular}

Sumber: Data primer yang diolah, 2020

Table 5 merujuk pada nilai Cronbach's Alpha atas keseluruhan variabel yang diteliti didapatkan melebihi 0,60 , sehingga diambil kesimpulan keseluruhan variabel yang diteliti lolos pada pengujian reliabilitas dan jawaban seluruh itemnya reliabel.

\section{Uji Normalitas}

Hasil Pengujian normalitas yaitu:

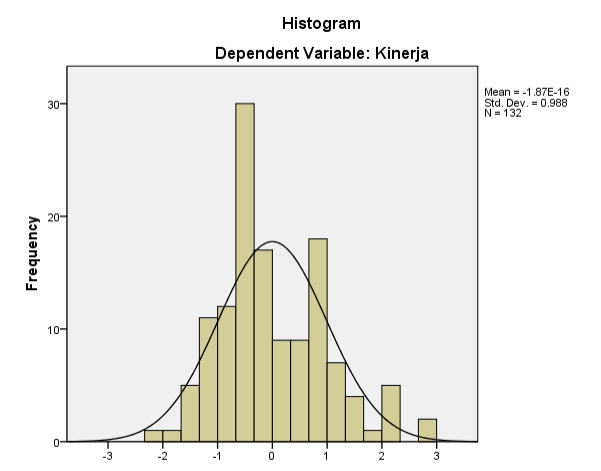

\section{Gambar 3. Uji Normalitas Histogram}

Sumber: Data primer yang diolah, 2020

Pada grafik merujuk pembentukan datanya riil menjadi kurva dengan kecenderungan simetri (U) tidak condong kanan maupun sehingga bisa dinyatakan distribusi data normal.

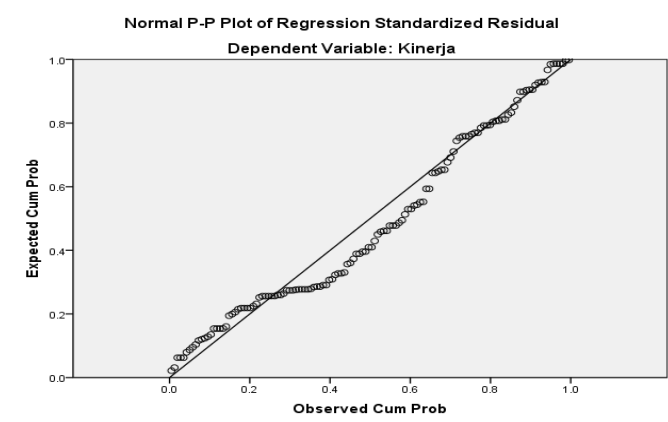

Gambar 4. Uji Normalitas P-P Plot

Sumber: Data primer yang diolah, 2020 
Gambar 4 merujuk dari grafik Normalitas P-P Plot diketahui persebaran garis diagonal yang banyak di sekitar garis diagonal. Artinya data pada penelitian mempunyai distrusi normal. Adapun pengujian normalitas statistik memanfaatkan Kolmogorov Smirnov.

Tabel 6.

Uji Normalitas Kolmogorov Smirnov

\begin{tabular}{|ll|r|}
\hline & & Unstandardized Residual \\
\hline $\mathrm{N}$ & Mean & 132 \\
Normal Parameters ${ }^{\mathrm{a}, \mathrm{b}}$ & Std. Deviation & .0000000 \\
& Absolute & 9.93171849 \\
Most Extreme Differences & Positive & .111 \\
& Negative & .111 \\
& & -.048 \\
Kolmogorov-Smirnov Z & & 1.274 \\
Asymp. Sig. (2-tailed) & & .078 \\
\hline
\end{tabular}

Sumber: Data primer yang diolah, 2020

Tabel 6 didapatkan nilai signifikansinya $0,078>0,05$. Oleh karenanya data merujuk pada distribusi secara normal.

\section{Uji Multikolinearitas}

Tabel 7.

Uji Multikolinearitas

\begin{tabular}{|c|c|c|c|c|c|c|c|}
\hline \multirow[t]{2}{*}{ Model } & \multicolumn{2}{|c|}{$\begin{array}{c}\text { Unstandardized } \\
\text { Coefficients }\end{array}$} & \multirow{2}{*}{$\begin{array}{c}\begin{array}{c}\text { Standardized } \\
\text { Coefficients }\end{array} \\
\text { Beta }\end{array}$} & \multirow[b]{2}{*}{$\mathrm{T}$} & \multirow[b]{2}{*}{ Sig. } & \multicolumn{2}{|c|}{ Collinearity Statistics } \\
\hline & $\mathrm{B}$ & Std. Error & & & & Tolerance & VIF \\
\hline $1 \quad$ (Constant) & 2.294 & 3.203 & & .716 & .475 & & \\
\hline Kompensasi & .484 & .124 & .303 & 3.887 & .000 & .887 & 1.127 \\
\hline Insentif & .268 & .123 & .173 & 2.183 & .031 & .861 & 1.162 \\
\hline GayaKepemimpinan & .272 & .069 & .302 & 3.941 & .000 & .916 & 1.092 \\
\hline
\end{tabular}

Sumber: Data primer yang diolah, 2020

Tabel 7 merujuk nilainya tolerance $>0,1$. Nilainya VIF variabel $<10$ bahwasannya pada penelitian yang dilaksanakan kompensasi, insentif dan gaya kepemimpinan tidak ditemukan multikolinearitas.

\section{Uji Heteroskedastisitas} terjadi:

Terdapat sejumlah metode guna menjadi pendeteksi heteroskedastisitas yang

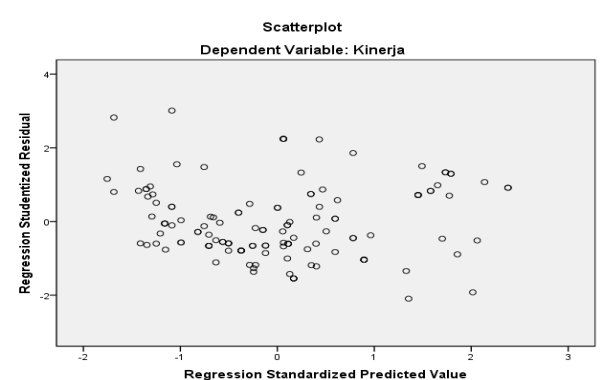

Gambar 1.3: Uji Heteroskedastisitas

Sumber: Data primer yang diolah, 2020 
Pada grafik merujuk persebaran titiknya dengan ketidakjelasan pola yakni pada sumbu Y dibawah maupun diatas angka nol (0), tidak terjadi pengumpulan pada sebuah tempat, oleh karenanya melalui grafik diambil kesimpulan pada permodelan regresi tidak ditemukan heteroskedastisitas.

Tabel 8

Uji Gletjer

\begin{tabular}{|c|c|c|c|c|c|c|}
\hline \multirow{2}{*}{\multicolumn{2}{|c|}{ Model }} & \multicolumn{2}{|c|}{$\begin{array}{c}\text { Unstandardized } \\
\text { Coefficients }\end{array}$} & $\begin{array}{c}\text { Standardi } \\
\text { zed } \\
\text { Coefficie } \\
\text { nts } \\
\end{array}$ & \multirow[b]{2}{*}{$\mathrm{t}$} & \multirow[b]{2}{*}{ Sig. } \\
\hline & & $\mathrm{B}$ & Std. Error & Beta & & \\
\hline \multirow[t]{4}{*}{1} & (Constant) & 4.598 & 1.841 & & 2.497 & .014 \\
\hline & Kompensasi & .066 & .072 & .085 & .917 & .361 \\
\hline & Insentif & .047 & .071 & .063 & .672 & .503 \\
\hline & GayaKepemimpinan & .040 & .040 & .091 & 1.004 & .317 \\
\hline
\end{tabular}

Sumber: Data primer yang diolah, 2020

Tabel 8 merujuk nilai signifikansinya $>0,05$ yakni heteroskedastisitas tidak terjadi.

\section{Model Penelitian}

Pada penelitian, uji hipotesis yang dimanfaatkan yakni melalui analisis regresi linier berganda. Permodelan yang dimanfaatkan yakni:

Tabel 9.

Hasil Analisis Regresi Linear Berganda

\begin{tabular}{|c|c|c|c|c|c|c|c|}
\hline \multirow[t]{2}{*}{ Model } & \multicolumn{2}{|c|}{$\begin{array}{l}\text { Unstandardized } \\
\text { Coefficients }\end{array}$} & \multirow{2}{*}{$\begin{array}{c}\begin{array}{c}\text { Standardized } \\
\text { Coefficients }\end{array} \\
\text { Beta }\end{array}$} & \multirow[b]{2}{*}{$\mathrm{T}$} & \multirow[b]{2}{*}{ Sig. } & \multicolumn{2}{|c|}{ Collinearity Statistics } \\
\hline & $\mathrm{B}$ & Std. Error & & & & Tolerance & VIF \\
\hline $1 \quad$ (Constant) & 2.294 & 3.203 & & .716 & .475 & & \\
\hline Kompensasi & .484 & .124 & .303 & 3.887 & .000 & .887 & 1.127 \\
\hline Insentif & .268 & .123 & .173 & 2.183 & .031 & .861 & 1.162 \\
\hline GayaKepemimpinan & .272 & .069 & .302 & 3.941 & .000 & .916 & 1.092 \\
\hline
\end{tabular}

Sumber: Data primer yang diolah, 2020

$$
Y=2,294+0,484 X_{1}+0,268 X_{2}+0,272 X_{3}+e
$$

Pada regresi linier berganda seperti tabel intinya yakni:

1. Konstanta yakni 2,070 menrangkan bahwasannya apabila tidak terdapat atau konstan variabel kompensasi, insentif dan gaya kepemimpinan sehingga kinerja karyawan pada 2,070 satuan.

2. Koefisien regresi variabel kompensasi yakni 0,484 serta memiliki nilai positif, merujuk bahwasannya setiap variabel kompensasi mengalamai kenaikan 1 satuan bisa membawa peningkatan variabel kinerja karyawan sebanyak 0,484 satuan dimana variabel lainnya dianggap sama.

3. Koefisien regresi variabel insentif yakni 0,268 dan memiliki nilai positif, merujuk bahwasannya setiap variabel insentif mengalami kenaikan 1 satuan bisa membawa peningkatan variabel kinerja karyawan sebanyak 0,268 satuan dimana variabel lainnya dianggap sama.

4. Koefisien regresi variabel gaya kepemimpinan yakni 0,272 dan memiliki nilai positif, merujuk bahwasannya setiap variabel gaya kepemimpinan mengalami kenaikan 1 
satuan bisa membawa peningkatan variabel kinerja karyawan sebanyak 0,272 satuan dimana variabel lainnya dianggap sama.

\section{Koefisien Determinasi Hipotesis}

Tabel 10.

Uji Koefisien Determinasi

Model Summary

\begin{tabular}{|c|r|r|r|r|}
\hline Model & \multicolumn{1}{|c|}{ R } & R Square & Adjusted R Square & \multicolumn{1}{c|}{$\begin{array}{c}\text { Std. Error of the } \\
\text { Estimate }\end{array}$} \\
\hline 1 & $.557^{\mathrm{a}}$ & .310 & .294 & 10.04743 \\
\hline
\end{tabular}

Sumber: Data primer yang diolah, 2020

Tabel 10 pengujian koefisien determinasi yang dihasilkan didapatkan nilainya Adjusted $R$ Square yakni 0,294 artinya 29,4\% variasinya variabel kinerja karyawan yang bisa diterangkan variabel kompensasi, insentif dan gaya kepemimpinan smentara sisa lainnya yakni $70,6 \%(100 \%-39,7 \%)$ diterangkan variabel lainnya yang tidak dikaji penulis, misalny konflik kerja, beban kerja, dorongan kerja serta lainnya.

\section{Pengujian Hipotesis Secara Simultan (Uji F)}

Pada hakekatnya statistik F merujuk seluruh variabel bebas yang masuk pada permodelan berpengaruh pada dependennya secara simultan.

Tabel 11.

Uji Simultan (Uji F)

ANOVA $^{\mathrm{b}}$

\begin{tabular}{|ll|r|r|r|r|r|}
\hline \multicolumn{1}{|l|}{ Model } & Sum of Squares & Df & Mean Square & F & Sig. \\
\hline 1 & Regression & 5805.347 & 3 & 1935.116 & 19.169 & $.000^{\mathrm{a}}$ \\
& 12921.713 & 128 & 100.951 & & \\
Residual & 18727.061 & 131 & & & \\
Total & & & & \\
\hline
\end{tabular}

Sumber: Data primer yang diolah, 2020

Tabel 11 merujuk kepada derajat bebasnya $1\left(\mathrm{df}_{1}\right)=\mathrm{k}-1=4-1=3$, dengan derajat bebasnya $2\left(\mathrm{df}_{2}\right)=\mathrm{n}-\mathrm{k}=132-4=128$, yang mana $\mathrm{n}=$ jumlahnya sampel, $\mathrm{k}=$ jumlahnya konstruk, nilai $\mathrm{F}_{\text {tabel }}$ dari taraf signifikansinya 0,05 ialah 2,68 . Mengacu uji yang dihasilkan didapatkan nilai $\mathrm{F}_{\text {hitung }}(19,169)>\mathrm{F}$ tabel $(2,68)$ serta probabilitas signifikansinya $0,000<$ 0,05 , artinya Ha diterima sedangkan Ho ditolak yakni dengan bersamaan Kompensasi, Insentif, dan Gaya Kepemimpinan mempengaruhi Kinerja Karyawan PT. Cipta Agro Sejati, Rokan Hilir, Riau secara signifikan dan positif.

\section{Pengujian Hipotesis Secara Parsial (Uji-t)}

Pengujian $t$ dimanfaatkan guna melihat pengaruh ataupun hubungan bermakna (signifikan) variabel independen terhadap dependennya secara parsial. 
Tabel 12.

Uji Parsial (Uji t)

Coefficients $^{\mathrm{a}}$

\begin{tabular}{|c|c|c|c|c|c|c|}
\hline \multirow{2}{*}{\multicolumn{2}{|c|}{ Model }} & \multicolumn{2}{|c|}{$\begin{array}{c}\text { Unstandardized } \\
\text { Coefficients }\end{array}$} & \multirow{2}{*}{$\begin{array}{c}\text { Standardized } \\
\text { Coefficients }\end{array}$} & \multirow[b]{2}{*}{$\mathrm{t}$} & \multirow[b]{2}{*}{ Sig. } \\
\hline & & B & Std. Error & & & \\
\hline \multirow[t]{4}{*}{1} & (Constant) & 2.294 & 3.203 & & .716 & .475 \\
\hline & Kompensasi & .484 & .124 & .303 & 3.887 & .000 \\
\hline & Insentif & .268 & .123 & .173 & 2.183 & .031 \\
\hline & GayaKepemimpinan & .272 & .069 & .302 & 3.941 & .000 \\
\hline
\end{tabular}

Sumber: Data primer yang diolah, 2020

Nilai tabel guna probabilitas 0,05 dengan derajat independen $(\mathrm{df})=132-4=128$ ialah sebanyak 1,979 . Artinya uji yang dihasilkan secara individual yakni:

1. Perhitungan uji hipotesis yang didapatkan secara individual didapatkan nilai $t_{\text {hitung }}>$ $\mathrm{t}_{\text {tabel }}$ ataupun 3,887 $>1,979$ dari signifikansi didapatkan $0,000<0,05$, artinya $\mathrm{Ha}$ diterima sementara Ho ditolak yakni dengan individual Kompensasi mempengaruhi Kinerja Karyawan PT. Cipta Agro Sejati, Rokan Hilir, Riau secara individual.

2. Perhitungan uji hipotesis yang didapatkan secara individual didapatkan nilai $t_{\text {hitung }}>$ $t_{\text {tabel }}$ maupun 2,183 $>1,979$ dengan signifikansi didapatkan $0,031<0,05$, artinya Ha diterima sementara Ho ditolak yakni dengan individual Insentif mempengaruhi Kinerja Karyawan PT. Cipta Agro Sejati, Rokan Hilir, Riau secara signifikan dan postif.

3. Perhitungan uji hipotesis yang didapatkan secara individual didapatkan nilai $t_{\text {hitung }}>$ $t_{\text {tabel }}$ ataupun 3,941 $>1,979$ dari signifikansi yang didapatkan $0,000<0,05$, artinya $\mathrm{Ha}$ diterima sedangkan Ho ditolak yakni dengan individual Gaya Kepemimpinan mempengaruhi Karyawan PT. Cipta Agro Sejati, Rokan Hilir, Riau.

\section{Pembahasan}

Perhitungan uji hipotesis yang dihasilkan secara individual didapatkan nilai thitung $>t_{\text {tabel }}$ maupun 3,887 $>1,979$ dari signifikansi didapatkan $0,000<0,05$, artinya Ha diterima sementara Ho ditolak yakni dengan individual Kompensasi memengaruhi Kinerja Karyawan PT. Cipta Agro Sejati, Rokan Hilir, Riau secara signifikan dan positif.

Penelitian yang dihasilkan juga selaras teori menurut (Edison et al., 2016:164), kompensasi yang layak memicu semangat individu guna peningkatan keahlian termasuk membuat komitmen pekerja terhadap organisasi ataupun perusahaan semakin kuat, Dan berujung pada peningkatan kinerja organisasi atau perusahaan termasuk individu.

Kompensasi menjadi penerimaan bagi karyawan atas kontribusinya kepada organisasi. Kompensasi finansial yang diberikan secara adil dan layak menjadi upaya pendekatam dan bentuk balas jasa. Oleh karenanya hendaklah ada rancangan kompensasi yang membuat karyawan menjadi puas serta prestasi kerja dapat dicapainya. Masalahnya karyawan mendapatkan kompensasi yang tidak menyesuaikan pengorbanan yang diberikan kepada perusahaan. Dimana kenaikan gaji yang kecil. Kompensasi yang diberikan kepada karyawan belum efektif. Hal ini terlihat dari beberapa jabatan di dalam perusahaan belum mendapatkan kompensasi berupa gaji yang sesuai dengan ketetapan minimal dari pemerintahan. Selain itu banyak karyawan mengeluhkan bahwa besar insentif yang tidak sebanding target yang perusahaan yang sudah ditentukan, tunjangan yang diberikan masih 
belum memuaskan disebabkan karyawan hanya menerima tunjangan uang makan dan BPJS. Fasilitas karyawan yang diterima masih belum lengkap dalam mendukung kinerja karyawan di dalam perusahaan. Hal ini mengakibatkan karyawan tidak termotivasi dalam bekerja sehingga mengakibatkan karyawan bekerja dengan maksimal di dalam perusahaan.

Perhitungan uji hipotesis yang dihasilkan secara individual didapatkan nilai $\mathrm{t}_{\text {hitung }}$ $>t_{\text {tabel }}$ ataupun 2,183 $>1,979$ dari signifikansi didapatkan $0,031<0,05$, maksudnya Ha diterima sementara Ho ditolak yakni dengan individual Insentif mempengaruhi Kinerja Karyawan PT. Cipta Agro Sejati, Rokan Hilir, Riau secara signifikan dan positif. Penenlitian yang dihasilkan sejalan dengan kajian yang dilaksanakan (Subianto, 2016) insentif mempengaruhi kinerja karyawan secara signifikan.

Sejalan dengan teori menurut (Priansa, 2016:336), insentif material yang diberikan oleh organisasi hendaknya melakukan pertimbangan kinerja. Wujudnya yakni pembayaran dimana mengacu kinerjanya selama di organisasi. Permasalahan insentif dalam perusahaan adalah besarnya insentif juga diduga sebagai bagian faktor yang memengaruhi kinerja karyawan pada perusahaan yang menurun. Permasalahan insentif adalah sedikitnya pemberian insentif. Besarnya insentif yang diberikan setiap karyawan berbeda sehingga banyak karyawan yang tidak memahami perhitungan insentif dan cara pengukuran yang diterima kecuali untuk insentif bagian pemasaran atau marketing, banyak karyawan yang sulit untuk mencapai target kerja terlihat dari banyak karyawan yang tidak menerima insentif setiap bulannya.

Perhitungan uji hipotesis yang dihasilkan secara individual didapatkan nilai thitung $>t_{\text {tabel }}$ maupun 3,941 $>1,979$ dengan signifikansi yang didapatkan $0,000<0,05$, artinya Ha diterima sementara Ho ditolak yakni dengan individual Gaya Kepemimpinan mempengaruhi Kinerja Karyawan PT. Cipta Agro Sejati, Rokan Hilir, Riau secara signifikan dan positif.

Terhadap PT. Cipta Agro Sejati, Rokan Hilir, Riau perlu adanya perbaikan kepemimpinan dan stress kerja karyawan. Perusahaan perlu memperbaiki secara bersamaan sehingga dapat meningkatkan kinerja karyawan secara keseluruhan. Dimana permasalahan kepemimpinan yang belum efektif baik dari segi untuk memotivasi karyawan dan sifat pemimpin yang tidak mempunyai kepedulian terhadap karyawan. Sedangkan stress kerja karyawan dipicu oleh beban kerja yang sangat tinggi. Dan pada perusahaan ini juga tak adanya penanggulan terhadap stress kerja sehingga karyawan mengalami stress yang berkepanjangan dalam pelaksanaan tugas dan tanggung jawabnya. Beberapa hal kepemimpinan dan stress kerja ini menyebabkan karyawan mempunyai kinerja yang belum efektif dan efisien.

\section{KESIMPULAN}

Perhitungan yang dihasilkan secara individual mengenai hipotesis yang diuji didapatkan nilai $t_{\text {hitung }}>t_{\text {tabel }}$ maupun 3,887 $>1,979$ dari signifikansinya $0,000<0,05$, maksudnya $\mathrm{Ha}$ diterima sementara Ho ditolak dimana Kompensasi dengan individual memberi pengaruh pada Kinerja Karyawan PT. Cipta Agro Sejati, Rokan Hilir, Riau dengan signifikan dan positif. Perhitungan yang dihasilkan secara individual mengenai hipotesis yang diuji didapatkan nilai $t_{\text {hitung }}>t_{\text {tabel }}$ ataupun 2,183 $>1,979$ dengan signifikansinya $0,031<0,05$, artinya Ha diterima sementara Ho ditolak dimana Insentif dengan individual memberikan pengaruh terhadap Kinerja Karyawan PT. Cipta Agro Sejati, Rokan Hilir, Riau dengan signifikan dan positif. Perhitungan yang dihasilkan secara individual mengenai hipotesis yang diuji didapatkan nilai $t_{\text {hitung }}>t_{\text {tabel }}$ maupun 3,941 $>1,979$ dari signifikansinya $0,000<$ 0,05, artinya Ha diterima sedangkan Ho ditolak dimana Gaya Kepemimpinan dengan individual memberi pengaruh pada Kinerja Karyawan PT. Cipta Agro Sejati, Rokan Hilir, Riau dengan signifikan dan positif. Dari keseluruhan hasil uji didapatkan nilai $\mathrm{F}$ hitung 
$(19,169)>F_{\text {tabel }}(2,68)$ serta probabilitas signifikansinya $0,000<0,05$, artinya Ha diterima sementara Ho ditolak dimana Kompensasi, Insentif, serta Gaya Kepemimpinan dengan bersama memberi pengaruh pada Kinerja Karyawan PT. Cipta Agro Sejati, Rokan Hilir, Riau secara signifikan dan positif.

\section{REFERENSI}

Arikunto, S. (2016). Prosedur Penelitian Suatu Pendekatan Praktik. Rineka Cipta. Bangun, W. (2018). Manajemen Sumber Daya Manusia (T. P. I (ed.)). Erlangga.

Edison, E., Anwar, Y., \& Komariyah, I. (2016). Manajemen Sumber Daya Manusia. Alfabeta.

Esti, Padmowiharjo, S., \& Tabroni. (2019). PENGARUH KEPEMIMPINAN TRANSFORMASIONAL DAN KOMPENSASI TERHADAP KINERJA KARYAWAN MELALUI INTEGRITAS SEBAGAI VARIABEL INTERVENING PADA KARYAWAN BANK BNI CABANG RAWAMANGUN. 4(1), 40-51.

Ghozali, I. (2016). Aplikasi Multivariate Dengan Program IBM SPSS 23. Universitas Diponegoro.

Husain, B. A. (2020). PENGARUH GAYA KEPEMIMPINAN TERHADAP KINERJA KARYAWAN PADA PT BIMA BANGUN SENTANA. KREATIF Jurnal Ilmiah Prodi Manajemen Universitas Pamulang, 7(1), 39-46. https://doi.org/2406-8616

Priansa, D. J. (2016). Perencanaan \& Pengembangan SDM (A. Garnida (ed.)). Alfabeta.

Priyanto, D. (2018). SPSS Panduan Mudah Olah Data Bagi Mahasiswa \& Umum (I). Andipublisher.

Rahayu, B., \& Ruhamak, M. D. (2017). PENGARUH KEPEMIMPINAN, INSENTIF, REMUNERASI DAN MOTIVASI TERHADAP KINERJA KARYAWAN (Studi Kasus Pada PT Industri Sandang Pangan Nusantara Cilacap). Jurnal Ekonomi Universitas Kadiri, 2(1), 1-22.

Robbins, S. P., \& Coulter, M. (2013). Manajemen (10th ed.). Erlangga.

Sangagji, S. (2016). Organisasi Dan Manajemen: Perilaku, Struktur, Budaya dan Perubahan Organisasi. Alfabeta.

Subianto, M. (2016). Pengaruh Gaji Dan Insentif Terhadap Kinerja Karyawan Pada Pt. Serba Mulia Auto Di Kabupaten Kutai Barat. EJournal Administrasi Bisnis, 4, 698712 .

Sudarmin Manik. (2016). Faktor-Faktor yang Mempengaruhi Pemberian Kompensasi pada Karyawan Bank. Al-Masraf: Jurnal Lembaga Keuangan Dan Perbankan, 1(2), 224229.

Sujarweni, V. W. (2015). Metodologi Penelitian Bisnis \& Ekonomi. PUSTAKABARUPRESS.

Sunarsi, D. (2018). Pengaruh Gaya Kepemimpinan, Motivasi Dan Disiplin Kerja Terhadap Kinerja Pendidik Yayasan Marvin. Inovasi, 5(1), 1. https://doi.org/10.32493/inovasi.v5i1.y2018.p1-18

Sunyoto, D. (2012). Teori, Kuesioner, dan Analisis Data Sumber Daya Manusia (Praktik Penelitian). CAPS (Center For Academic Publishing Services).

Wibowo. (2014). Manajemen Kinerja (4th ed.). Rajawali Press.

Wijaya, T., Bisnis, P. M., Manajemen, P. S., Petra, U. K., \& Siwalankerto, J. (2012). Pengaruh Kompensasi Terhadap Kinerja Karyawan Pada Pt Sinar Jaya Abadi Bersama. 3(2).

Yancomala, O. (2014). Hubungan Gaya Kepemimpinan dengan Motivasi Kerja Pegawai di Dinas Pemuda dan Olahraga Provinsi Sumatera Barat. Jurnal Administrasi Pendidikan, 2(1), 535-541.

Yani, M. (2012). Manajemen Sumber Daya Manusia. Mitra Wacana Media. 